BULLETIN Bulletin hispanique

HISPANIQUE Université Michel de Montaigne Bordeaux

$113-2$ | 2011

Varia

\title{
Por las últimas sendas de la creación
}

los «Proyectos de cuentos» de Pedro Salinas

\section{Natalia Vara Ferrero}

\section{(2) OpenEdition}

Journals

Edición electrónica

URL: http://journals.openedition.org/bulletinhispanique/1415

DOI: 10.4000/bulletinhispanique. 1415

ISSN: 1775-3821

Editor

Presses universitaires de Bordeaux

\section{Edición impresa}

Fecha de publicación: 1 diciembre 2011

Paginación: 585-609

ISBN: 978-2-86781-793-9

ISSN: 0007-4640

\section{Referencia electrónica}

Natalia Vara Ferrero, «Por las últimas sendas de la creación », Bulletin hispanique [En línea],

113-2 | 2011, Publicado el 01 diciembre 2014, consultado el 04 mayo 2019. URL : http://

journals.openedition.org/bulletinhispanique/1415; DOI : 10.4000/bulletinhispanique.1415 


\title{
Por las últimas sendas de la creación: los «Proyectos de cuentos» de Pedro Salinas
}

\author{
Natalia Vara Ferrero \\ Ikerbasque (Basque Foundation for Science) - University of Chicaco
}

Le fonds d'archives de Pedro Salinas est non seulement indispensable à la connaissance de l'auvre mais, également, à celle - moins répandue - de certains genres littéraires cultivés par l'écrivain. Le présent article aborde les "Projets de contes» : documents qui révèlent de façon exceptionnelle la façon dont naissaient et se développaient les premières phases de l'écriture narrative de Salinas. À travers une étude de type génétique, on examine les doutes et les certitudes qui ont déterminé les voies de son écriture, offrant ainsi au lecteur un accès privilégié à l'intimité de l'«atelier de l'écrivain».

El archivo de Pedro Salinas es indispensable no sólo para conocer el valor de su obra, sino también resulta necesario para completar el conocimiento de algunos de los géneros que trabajó el escritor. Este artículo aborda los "Proyectos de cuentos", documentos que desvelan de modo excepcional cómo surgían y se desarrollaban las primeras fases de la escritura narrativa saliniana. A través de un estudio de tipo genético se examinan dudas y certezas que determinaron sus caminos escriturales, permitiendo al lector acceder a la intimidad de su «taller del escritor».

Pedro Salinas' archive collection is essential, not only to know the value of his work, but also to complete the information about the genres cultivated by the writer. This paper deals with his "Proyectos de cuentos", documents that show how the first stages in his narrative writing process emerged and developed. The doubts and certainties that determined his writing process are examined through a genetic kind of research, in order to enhance the reader's vision of his private "writer's workshop".

Mots-clés: Pedro Salinas - Fonds d'archives - Manuscrits - CEuvre narrative Critique génétique.

Bulletin Hispanique, Tome 113, nº 2 - décembre 2011 - p. 585 à 609. 


\section{Tendiendo nuevos puentes de CONOCIMIENTO: LA CRÍTICA GENÉTICA}

En los últimos años se ha producido un interesante cambio en la perspectiva crítica desde la que se afronta el estudio de los materiales previos y complementarios del texto que se considera definitivo, esto es, aquel que el autor decide publicar ${ }^{1}$. Una parte de los estudiosos han variado el prisma, subvirtiendo la jerarquía de sus objetos de investigación. Se ha pasado de considerar el texto publicado como un elemento acabado, perfecto y ejemplo de la culminación de las ambiciones escriturales del autor, a prestar atención al largo y arduo proceso que desemboca en esa versión última. Esta aproximación crítica ha descubierto al ámbito de la investigación filológica el estatus dual de estos textos, su naturaleza tanto material como intelectual que acoge ni más ni menos que los avatares de un proceso de escritura (Hay: 2008, pág. 41). Los estudios genéticos, en definitiva, han subvertido la jerarquía de intereses, poniendo el acento en el proceso, con todas las posibilidades descartadas o exploradas; se ha producido así la ampliación del interés de la crítica tradicional, hasta hace muy poco centrada únicamente en alcanzar un hipotético estado ideal en el texto publicado. De hecho, hay quien mantiene que "no se trata de la mera inversión de una dinámica, se trata de un nuevo objeto de análisis: la escritura en proceso» (Lois: 2001, pág. 46).

Estudiosos como Jean Bellemin-Noël defienden la importancia de estos materiales, aduciendo que:

Los borradores alzan el vuelo sobre la producción (en sentido dinámico), sobre la elaboración de un producto acabado. Informan en cuanto a los antecedentes del libro publicado, proporcionan su historia interior, cronología de una redacción y arqueología de un texto. Pues los borradores en tanto que forma inacabada -0 , con mayor exactitud: formación en vías de acabado- dan una idea general de las intenciones del escritor [...] sugieren el sentido de un proyecto por el hecho mismo de que ponen al día las renuncias, las reorientaciones, la manera en que ha parecido necesario o preferible rectificar un itinerario; la búsqueda del «mejor estado del texto» es revelador de lo que el autor invertía en su escrito (2008: pág. 57)

1. Este artículo está vinculado al proyecto «Direcciones estéticas de la lírica posmoderna en España» (Ref. FFI2009 - 11728). 
Las raíces de este cambio de perspectiva hay que buscarlas en Francia en los ańos 70 gracias al deseo de acometer el estudio de algunas colecciones de manuscritos modernos desde una perspectiva novedosa. La aproximación de Louis Hay a los manuscritos de Heinrich Heine y el estudio que Jean Bellemin-Noël llevó a cabo sobre un poema de Czeslaw Milosz inauguraron una senda (Lois: 2001, pág. 48; Pastor Platero: 2008, pág. 19) en la que los papeles que han ido conformando el "taller del escritor» pasan de ser considerados objetos de colección y exhibición a convertirse en el medio para «observar la estructura plena y viva de una escritura en estado naciente, su desarrollo, sus metamorfosis, las dificultades de su evolución. En otras palabras, [permiten al investigador comprender] la formación progresiva de la obra» (Pastor Platero: 2008, pág. 10). El enfoque de los estudios genéticos no se conforma con la clasificación, ordenación y transcripción del material que testimonia un proceso de escritura, va más allá procediendo a su interpretación. Esta labor que se puede realizar desde diversos enfoques (psicoanalítico, sociocrítico, lingüístico, etc.) permite desarrollar una interpretación múltiple que tiende puentes interdisciplinarios para ofrecer una lectura exhaustiva.

Los estudios y ediciones críticas resultantes demuestran que esta aproximación a los borradores ha gozado de una gran acogida en Latinoamérica, donde trabajos como el que Amado Alonso realizó sobre el Fausto de Estanislao del Campo y el estudio sobre el Cuaderno de bitácora de «Rayuela» que llevó a cabo Ana María Barrenechea preceden a la aparición de la magnífica "Colección Archivos», que ha tratado de aunar en sus textos el proceso de escritura, el estadio final que se alcanza con la publicación y la recepción de algunos de los textos más importantes de la literatura latinoamericana (Colla: 2005). Lamentablemente, ese movimiento de análisis y edición de los diversos materiales "pre-textuales» no ha gozado del mismo interés por parte de la crítica espańola. Como un buen conocedor de este ámbito ha puesto de manifiesto, se trata de un movimiento de estudio poco conocido entre el hispanismo peninsular, donde los estudios de edición que han gozado de mayor interés, los medievales y del Siglo de Oro, no ofrecían la opción de conocer materiales anteriores a la versión publicada, sino más bien la trayectoria editorial posterior. Sin embargo, los materiales pretextuales de Benito Pérez Galdós, Emilia Pardo Bazán, Max Aub y los autores de la Edad de Plata cuyo archivo se custodia parcialmente en la Residencia de Estudiantes han conseguido despertar interés, aunque sus posibilidades no hayan sido aún plenamente exploradas (Lluch Prats: 2007). Este es el caso del escritor que centrará el interés de este trabajo: Pedro Salinas. 


\section{Los «Proyectos de Cuentos»:}

\section{DE LA RELEVANCIA DE LOS MATERIALES EMBRIONARIOS}

El 28 de mayo de 1975 la biblioteca Houghton de la Universidad de Harvard recibió un valioso legado. Los hijos de Pedro Salinas, Soledad Salinas de Marichal y Jaime Salinas, depositaron el archivo de su padre en esta institución, especializada en preservar en condiciones ideales de conservación todo tipo de raros y manuscritos. Bajo la denominación bMS Span 100 se clasificaron las 71 cajas de las que se compone el archivo de Pedro Salinas. En ellas el investigador puede encontrar una cantidad ingente de material, que abarca desde manuscritos y borradores de su obra poética, teatral, ensayística y narrativa hasta una gran cantidad de cartas y apuntes para conferencias y su actividad docente, además de diversos objetos personales como pasaportes y fotografías familiares, libretas, agendas, recortes de periódicos con críticas literarias e, incluso, unas gafas pertenecientes al escritor. Desde 1992 el investigador que quiera consultarlo en España puede tener acceso a la copia que existe en la Residencia de Estudiantes de Madrid; este material, antes microfilmado y ahora digitalizado, ofrece la oportunidad de acceder al archivo completo de la biblioteca Houghton. No obstante, se debe puntualizar que, dispersos en instituciones como el Wellesley College de Massachusetts o la Universidad de Río Piedras en Puerto Rico, en las que Salinas ejerció su labor docente, se encuentren también otros materiales pertenecientes al escritor.

Aunque estos materiales se hallan catalogados, mucha es aún la labor de identificación, valoración y análisis que queda aún pendiente (en parte, para remedar ciertos errores de la clasificación existente ${ }^{2}$ ). En los últimos años la edición de las Obras completas del autor ha contribuido no poco al rastreo de diversos materiales del archivo del autor. Cabe destacar la edición de diversas cartas, ensayos y poemas que no habían visto la luz o que habían aparecido dispersos en revistas o libros. Y, sobre todo, la revisión de borradores de algunos de sus textos teatrales, como El director, del que existe un borrador que presenta diversas variantes con respecto al texto publicado, algunas de

2. Como señaló Monserrat Escartín en el «II Congreso Internacional de Manuscritos Literarios. Edición Crítica y Genética de Autores Contemporáneos (siglos XIX-XXI)» celebrado en CILENGUA en San Millán de la Cogolla los días 9, 10 y 11 de diciembre de 2009, se produjeron errores graves en la catalogación del archivo. Valga como ejemplo el siguiente: en la parte del archivo que recoge las cartas enviadas a Katherine Whitmore el investigador descubre que los poemas que se hallaban en las misivas fueron separados de ellas, perdiendo así gran parte de la información que podían aportar (datación, circunstancias de su escritura, posibilidad de una ordenación por fases de escritura...). 
las cuales Enric Bou ha incluido en su edición del teatro completo ${ }^{3}$. Aun así, es mucho el material que queda pendiente de estudios que permitan ampliar, matizar y profundizar la apreciación de la diversidad de niveles de la escritura saliniana.

Tomemos como ejemplo uno de los géneros que la crítica ha considerado secundario dentro de la obra del autor, la narrativa, caracterizado por la cantidad y la significación de este material, que será el que centre la atención en esta aproximación a su «taller». Son diversos los archivos de carácter narrativo que el estudioso encuentra en el archivo de Salinas. Entre ellos, evidentemente, no se halla rastro alguno de los materiales anteriores a su partida de España en 1936. Ni de "Un conocido por conocer», breve relato publicado en 1921 en el número 3 de la revista Índice (Revista de definición y concordia), ni tampoco de Vispera del gozo, colección de relatos de 1926. Su precipitada partida de Espańa el último día de agosto de 1936 y los desastres de la contienda determinaron la pérdida de una parte importante de los papeles del escritor.

Pese a estas importantes ausencias, el material narrativo depositado en la biblioteca Houghton presenta un carácter múltiple, aunque también ciertamente problemático. Una revisión exhaustiva induce al investigador a concluir que el conocimiento de su valioso archivo permite ampliar el corpus de la narrativa de Pedro Salinas, hasta ahora limitado a las tres obras que recoge su bibliografía: Vispera del gozo (1926), La bomba increíble (1950) y El desnudo impecable y otras narraciones (1951). De hecho, lo habitual por parte de la crítica ha sido ignorar el primer relato del autor, olvidado tal vez por su publicación aislada y temprana en una revista periódica, como la dirigida por Juan Ramón Jiménez. Los materiales que custodian estas cajas invitan a reflexionar sobre el lugar que este género ocupa en el conjunto de su obra y, sobre todo, a penetrar en la red de motivos, inquietudes, estrategias y géneros que componen la totalidad de su escritura narrativa. Es más, este archivo ofrece al lector la oportunidad de superar las limitaciones del texto final para adentrarse en un terreno lleno de sorpresas: el proceso escritural de su narrativa del exilio. En definitiva, una revisión sosegada y equilibrada permite examinar nuevamente los equívocos juicios que han rodeado su recepción crítica.

3. El editor señala al respecto en las Obras completas de Pedro Salinas que de «El director, la primera obra teatral escrita por Salinas, se conservan en Houghton dos versiones muy diferentes, en especial del primer acto. Al no ser esta una edición crítica no se reproducen todas las variantes, pero sí se indican en nota algunas de las más importantes» (2007 vol. I: pág. 1148). 
La narrativa de Pedro Salinas, a la luz de los documentos de su archivo, es mucho más compleja de lo que la bibliografía de sus obras publicadas haría sospechar. Estos textos, inéditos en su mayoría, completan la visión parcial que se ha mantenido hasta la actualidad y esbozan un panorama plagado de silencios, dudas y planes. Los borradores de La bomba increíble [bMS Span 100 (1006)-(1007)] y de El desnudo impecable y otras narraciones [bMS Span 100 (1009)-(1018)] ofrecen al investigador la oportunidad de adentrarse por los recovecos de las diversas fases de escritura. Existen dos versiones de La bomba increíble que muestran la búsqueda escritural de un texto que respondiera a sus expectativas. De hecho, hay incluso una carpeta en la que se encuentran los cinco primeros capítulos de esta fabulación traducidos al inglés [bMS Span 100 (1008)], lo que demuestra el interés que tenía el autor por que el texto viera la luz en el país donde fue escrito. Los borradores redaccionales de El desnudo impecable y otras narraciones presentan mayor complejidad, pues corresponden a las diversas fases que caracterizan a las cinco novelas breves que componen el volumen. La primera, "El desayuno», presenta un único borrador; en cambio de la última, «El autor novel», existen tres. De las tres restantes existen dos borradores de cada una, por lo que resulta evidente que cada narración era afrontada de un modo por el autor, sin someterse a un esquema fijo e inalterable ${ }^{4}$.

No obstante, los problemas a los que se enfrenta el investigador que se adentra aún más en los documentos narrativos de este archivo son diversos. Por un lado, debe hacer frente a una clasificación y ordenación no siempre acertada, lo cual probablemente se debe a haber sido llevada a cabo por alguien con un conocimiento insuficiente del castellano. Eso explicaría la sorpresa que esconde el apartado de no-ficción. Éste se divide, por un lado, en libros, y, por otro, en artículos y ensayos; en este segundo subapartado, junto a otros archivos, se encuentra bajo la signatura bMS Span 100 (1054) un texto con un curioso nombre: «Los cuatro grandes mayúsculos y la doncella Tibérica». Se trata de tres copias en papel carbón, mecanografiadas y corregidas posteriormente a mano, con seguridad, por su autor. Este texto, fechado en mayo de 1946, no corresponde, de ninguna manera, con las categorías de artículo o ensayo. Su propio autor estableció su pertenencia genérica en una misiva enviada a su amigo Jorge Guillén poco después de la escritura del primer borrador: «Estos días que he estado echado en la cama, como no podía más que borrajear con lápiz, escribí, por razón puramente catártica, por desahogarme, un cuento titulado 'Los cuatro grandes'» (2007 vol. II: pág. 1082).

4. El lector interesado puede encontrar un apartado completo dedicado a este aspecto de los borradores del archivo saliniano en mi tesis doctoral, La narrativa de Pedro Salinas (2010). 
Resulta innegable que en la catalogación del archivo se incurrió en ciertas negligencias que no han sido subsanadas, pues desde la primera línea se hace evidente su carácter narrativo. Este «cuento» altera decisivamente la visión de la narrativa saliniana por varias razones. Tomando como base los datos ofrecidos por el autor, supone considerar que había retomado su escritura en este género, por lo menos, cuatro años antes de lo que se había creído. Asimismo, demuestra que existen más obras narrativas que las que se conocían hasta la actualidad y desvela una línea genérica y argumental desconocida, caracterizada por su entronque con el género de la sátira y su afinidad con el estilo irónico como arma de ataque literario contra Franco y los Aliados 5 .

Por otro lado, los textos que se encuentran en este archivo han debido enfrentarse al desinterés de la crítica y a la voluntad de la familia de no publicar aquellos proyectos que el escritor no culminó, lo que los ha sumido en un silencio de muchos años. Convenientemente clasificados en el apartado de prosa, específicamente en el de prosa ficticia, bajo las signaturas bMS Span 100 (1019) y (1020) se hallan dos eslabones perdidos sin los cuales resulta incompleto el conocimiento de la obra narrativa saliniana. El primero de ellos se denomina El valor de la vida y, como se resalta en el índice del archivo, se trata del manuscrito y los materiales preparatorios de una novela inacabada. La información que al respecto aportan las cartas del escritor con su esposa y con Jorge Guillén, resulta clave para conocer este proceso redaccional. Estas confesiones, paralelas al desarrollo escritural que se prolongó a lo largo de los primeros meses de 1949, constituyen un elemento fundamental para iluminar su primera y conflictiva inmersión en el género novelesco, pues desvelan las claves que determinan el incierto proceso y las razones del abandono una vez finalizada la primera parte. Por suerte para el lector actual, El valor de la vida, acaba de ver la luz de la mano de José Paulino Ayuso en la editorial Renacimiento ${ }^{6}$.

El segundo archivo, el que se halla bajo la signatura bMS Span 100 (1020), se denomina «Proyectos de cuentos» y consta de dos carpetas en las que se

5. Esta narración, que es una sátira paródica que responde a la negativa de los Aliados a intervenir en España, verá la luz en 2010 en la editorial Devenir bajo el título Dos prosas inéditas (entre la ironía y la sátira), que incluirá también otro texto satírico del autor, «A la sombra del paraguas en flor", en el que el blanco de su escritura irónica es Neville Chamberlain.

6. Con una introducción en la que se explora la narrativa del autor, José Paulino Ayuso nos ofrece una edición del texto en la que sin embargo se ha prescindido de casi todo el desarrollo del proceso escritural, esto es, de las huellas visibles que permitirían al lector entender en todos sus matices la evolución de la novela, pues únicamente se señalan algunas alternativas desechadas. 
consignan unas decenas de folios en los que el escritor plasmó proyectos de relatos y apuntes de ideas para futuros proyectos narrativos. Estos bosquejos han permanecido inéditos durante sesenta ańos ${ }^{7} \mathrm{y}$, sin embargo, constituyen el mejor testimonio del impulso dominante de su última etapa: «me siento con ganas de escribir mayores cada día. Sigo emperrado en lo narrativo: me rondan varios temas de cuentos» (2007 vol. III: pág. 1395). La importancia de estos esbozos se halla en que alumbran de un modo extraordinario las primeras huellas de un proceso creativo truncado, interrumpido casi en su nacimiento, a la espera de una reanudación imposible. Iluminan la visión de los primeros movimientos de un proceso apasionante, compuesto por un complejo devenir donde la escritura, la lectura y la reescritura se constituyen como ejes centrales. El valor de estos proyectos narrativos se encuentra en que constituyen "la oportunidad de un texto» (Bellemin-Noël: 2008, pág. 59) truncada y olvidada.

\section{Nómina de los «Proyectos De Cuentos»}

Los materiales embrionarios de carácter narrativo que se encuentran en estos archivos son los siguientes:

«Proyectos de cuentos». Carpeta 1

- «La partida de ajedrez»: Un folio, escritura mecanográfica. Recto: título y texto.

- «La impostora»: Un folio, escritura mecanográfica. Recto: título y texto. Verso: Carta oficial de una institución universitaria desconocida (probablemente Johns Hopkins).

- «Los falsificadores»: Un folio, escritura mecanográfica. Recto: título y texto. Verso: texto (reformulación del relato).

- «Las dos monedas»: Un folio, escritura mecanográfica. Recto: título y texto. Verso: Carta oficial de la Universidad Johns Hopkins.

- «Apuntes de temas»: Un folio, escritura mecanográfica y manual. Recto: Lista de ideas. Verso: Carta oficial de la Universidad Johns Hopkins.

7. José Paulino Ayuso recoge en su edición de El valor de la vida algunos de estos textos, «nada más que algunos escritos a máquina, como simple muestra de la fecunda dedicación de Salinas y también de la insistencia en temas habituales en esos años», "[Bocetos, proyectos y resúmenes de cuentos]" (2009: pág. 412). Los escritos recogidos son: "La impostora», "Las dos monedas», "Los estragos de la ilusión o los anuncios. El moralista», "La muerte vencida o los progresos de la ciencia» y «La ruptura», (2009: págs. 412-417). El editor se limita a fijar los textos y a señalar alguna errata. 
- «Los estragos de la ilusión o Los anuncios. El moralista»: Un folio, escritura mecanográfica. Recto: títulos y texto.

- «La muerte vencida o los progresos de la ciencia»: Un folio, escritura mecanográfica. Recto: títulos y texto.

- «Los inseparables o el desconsolado esposo»: Un folio, escritura mecanográfica. Recto: títulos y texto.

- (Relato): Seis folios manuscritos. Escritos en recto y verso en hojas de la compañía marítima Holland-America Line, únicamente texto. Los tres primeros folios presentan una textura más fina y son más grandes, los segundos de menor tamaño y más gruesos. En los tres últimos se percibe el corte lateral que señala que han sido arrancados de un cuaderno. Las alusiones realizadas en sus cartas permiten datar este texto en los últimos días de julio y los primeros de agosto de 1949, en el transcurso de un viaje que realizó a Europa en un barco de la Holland-America Line ${ }^{8}$.

«Proyectos de cuentos». Carpeta 2

- «El crimen»: Un folio, escritura manual. Recto: Título y texto. Verso: Texto.

- «La ruptura»: Un folio, escritura mecanográfica. Recto: Título y texto.

- «El botín planificado»: Un folio, escritura mecanográfica en tinta de color rojo. Recto: Título y texto.

- «La apuesta»: Un folio, escritura manual con tinta azul. Recto: Título y texto. Verso: Versos de las Coplas por la muerte de su padre de Jorge Manrique, la Epistola moral a Fabio de Andrés Fernández de Andrada y «El salmo XVIII» de Francisco de Quevedo?.

8. En una carta del 26 de julio, Pedro Salinas le confiesa a su esposa que la «seńora francesa, compañera de mesa, que es un ser vulgarísimo, me ha dado la idea de escribir una novelita corta. ¡Si ella supiera el papel que la reservo! Probablemente no haré nada porque no tengo máquina, pero me divierto pensándolo, y lo dejaré anotado, para ese día que nunca llega en que pueda escribir algo de lo que quiero" (2007 vol. III: págs. 1305-1306). Los editores del epistolario en las Obras completas, Enric Bou y Andrés Soria Olmedo, conjeturan que puede tratarse de «algún personaje de 'El desayuno' o 'Los inocentes' de El desnudo impecable u otras narraciones» (2007 vol. III: pág. 1625), pero a la vista de los datos que aporta el autor y los folios que se encuentran en el archivo resulta lógico suponer que la alusión se refiere a este proyecto que, efectivamente, anotó en unas páginas de la Holland-America Line.

9. Todos ellos tienen en común su forma poética, su carácter moral y la posición central de la metáfora de la existencia como río que desemboca en el mar: «Nuestras vidas son los ríos/ que van a dar a la mar, que es el morir» de Las coplas a la muerte de su padre de Jorge Manrique, «Como los ríos que en veloz corrida/ se llevan hacia el mar, tal soy llevado/ al último suspiro de mi vida» de la Epistola moral a Fabio de Andrés Fernández de Andrada y «Antes de que sepa andar el pie, se mueve/ camino de la muerte, donde envío/ mi vida oscura: 
- (Apuntes de ideas, sin título): Dos folios, escritura mecanográfica y manual con tinta verde. Recto folio 1: Listas de ideas, escritura mecanográfica y manual. Verso: Listas de ideas, escritura manual. Recto folio 2: Listas de ideas, escritura mecanográfica y manual. La temática de estos «apuntes» señala que se puede tratar de materiales preparatorios de La bomba increíble, por lo que podrían datarse hacia finales de 1949 o principios de 1950.

«Últimos escritos». Carpeta 2

- (Proyecto, sin título): Un folio, escritura manual a lápiz. Recto: texto. Verso: texto. Por su situación en esta carpeta, este texto debe pertenecer a 1951, a los últimos textos en los que trabajó el escritor antes de su fallecimiento.

\section{Proyectos y APUNTES: UNA PROPUESTA DE ANÁLISIS}

Hay trece textos breves que se encuentran en un estado embrionario de la escritura: ofrecen ya las líneas principales del argumento aunque se hallen en el estadio previo a un futuro desarrollo redaccional. Junto a ellos, se halla otro grupo de folios de menor cuantía, que se diferencia de estos porque recoge ideas que podrían utilizarse para la elaboración de posibles relatos, pero no plantean propiamente un argumento narrativo complejo. El conjunto que forman estos documentos ofrece al investigador la posibilidad de conocer un material naciente, fosilizado en las primeras fases de su desarrollo, una plasmación perfecta de los desequilibrios que caracterizan a los materiales preparatorios. Carecemos de datos que permitan conocer si estos textos, o algunos de ellos, fueron descartados por el escritor o, por el contrario, si fue la muerte la que frustró su desarrollo. Pese a esa indeterminación, conservan su valor como gérmenes de un programa narrativo, por lo que ofrecen una visión excepcional de las inquietudes y motivos que caracterizaban el «taller del autor» en su última época, sin lugar a dudas la que presenta «una mayor dosis de libertad y espontaneidad» (Lois: 2005, pág. 59).

Estos esbozos suponen el proceso de formación inicial de un proyecto inmerso en un estadio de endogénesis ${ }^{10}$. En algunos casos constituyen el

pobre y turbio río,/ que negro mar con altas hondas bebe» del «Salmo XVIII» de Francisco de Quevedo.

10. Pierre-Marc de Biasi defiende que la «endogénesis designa todo proceso escritural centrado en la elaboración de la escritura por sí misma: el paso reflexivo y autorreferencial de un trabajo en el que la materia ante-textual se transforma por los únicos recursos de la 
paso previo a la fase plenamente redaccional (las listas de ideas) y en otros la primerísima parte de esa fase (los esbozos de cuentos). Por sus características podemos identificarlos como lo que Élida Lois denomina «materiales prerredaccionales», esto es, argumentos, bosquejos e ideas que preceden a la redacción del proyecto o que suponen esa primerísima textualización (2001: pág. 2). Este tipo de material desvela la intimidad del proceso preparatorio, pues tiene una función que no es más ni menos que la «formulación del anteproyecto» narrativo (Biasi: 2008, pág. 120). La heterogeneidad que los caracteriza influye en los problemas de datación con los que se encuentra el investigador, pues no existe ninguna anotación al respecto y escasísimas son las referencias realizadas por el autor en los materiales paratextuales ${ }^{11}$. No aparecen numerados, así que es de suponer que no presentan un orden ni cronológico ni lógico ni temático, sino relacionado con la ordenación del archivo posterior a la muerte del autor.

El material que forma parte de los «Proyectos de cuentos» presenta una apariencia heterogénea, con un alto grado de hibridación tanto en los textos como en sus soportes. Varios esbozos se sitúan en el reverso de escritos oficiales o folios ya utilizados para otros asuntos, mientras otros figuran en impolutas páginas. Los menos se plasman en folios comerciales caracterizados por el logotipo identificativo de una empresa. Esta multiplicidad desvela la dinámica de un escritor para el que cualquier papel resulta válido para anotar un posible proyecto, dispuesto a dar cuenta de ese embrión narrativo en cualquier material susceptible de ser utilizado para tal fin, antes de que la inspiración huya.

La naturaleza de «Proyectos» remite a una clasificación binaria:

1) Apuntes de ideas, esto es, materiales pretextuales pertenecientes a una fase prerredaccional dominada por una visión impresionista de algunos aspectos de la realidad. Se trata de borradores que exploran líneas narrativas, que anotan lo que podría ser denominado «eje central» de una hipotética narración futura. Constituyen una fase absolutamente inicial, tras la que se desarrollaría el consiguiente proceso escritural en caso de que alguna de

escritura, ya se trata de un trabajo de exploración, de concepción, de estructuración o de textualización» (2008: pág. 131).

11. Fernando Colla señala la importancia de los «documentos paratextuales», esto es, aquellos documentos que «podían contener información significativa sobre la génesis de una obra (o, incluso, poseer fragmentos que se integran en esa génesis, que forman parte -como germen de figuras, de episodios, de direcciones narrativas- de la "masa escritural" de esa obra), correspondientes a las más variadas categorías, niveles y perspectivas» (2005: pág. 206). Pese a la importancia que presentan materiales como los epistolares en relación con el resto de la narrativa saliniana, en el caso de los «Proyectos de cuentos» las referencias son casi inexistentes. 
esas ideas fuese desarrollada. Se trata, en definitiva, del punto de partida del proceso de escritura de una narración. Estos apuntes constituyen un material ante-textual que testimonia una búsqueda de caminos, un abanico de notas exploratorias del que únicamente algunas pasarán a las siguientes fases y otras quedarán descartadas, testimoniando caminos truncados.

Los «apuntes de ideas» testimonian la chispa que prende el movimiento en el proceso del "taller de escritura» de la narrativa de Pedro Salinas. Esta primerísima fase presenta multitud de particularidades que sirven para que se puedan conocer las primeras huellas del desarrollo textual. Su apariencia no es en absoluto homogénea, pueden consignarse en un tipo de escritura (mecanográfica) o bajo una apariencia híbrida (escritura manual y mecanográfica). Esta forma dual de la escritura demuestra que cualquier estrategia resultaba aceptable con el fin de fijar las ideas que podrían encajar en un futuro proyecto narrativo. Es posible que el autor se preocupara de recoger ideas apuntadas previamente, por lo que no resulta en absoluto descartable que constituyan, en algún caso, una reescritura.

Estos «apuntes de ideas» aportan una información sustancial sobre las claves que caracterizaban la primera fase del proceso. En lo que se refiere a la lengua utilizada, destaca la forma telegráfica que adoptan las oraciones, breves y determinadas por una férrea voluntad de recoger con economía lingüística lo nuclear de una realidad determinada. Se omiten los verbos y todas aquellas estructuras o expresiones que no sean absolutamente imprescindibles. Generalmente, ponen de manifiesto una sobriedad expresiva que se resuelve con estructuras de tipo «sujeto+adjetivo»: «monedero falso» (claramente, un guiño a Los monederos falsos de André Gide), «música plácida» o "sueño lento». Otras de las construcciones que reflejan sintética y claramente la información principal son las especificativas. Este tipo de oraciones permite matizar la situación problemática en la que se encuentra el personaje: «el hombre que nunca habla lo suyo" y "la mujer que lleva un diario». El uso de los dos puntos también apunta hacia la concreción de la idea mediante la relación de causa o de consecuencia: «extirpación del pasado: operación» o «el criminal: el lector». Las enumeraciones y bimembraciones apuntan hacia esa línea de mesura verbal y búsqueda de la información nuclear, mostrando los rasgos imprescindibles del conflicto y delimitando su ámbito: «Recreo: sala de cine, sillones, música plácida» o «Ni tierra, ni fuego, sirven». Otra de las estructuras preferentes es aquella que permite unir sustantivos para mostrar su relación a través de la preposición «de»: «abolición del sentimiento del tiempo» o "supresión de día y noche».

Los apunte de ideas articulan, evidentemente, conjuntos unidos por ejes temáticos e inquietudes comunes. Parece indudable que se trata de una 
estrategia característica de la primera fase del proceso escritural, centrada en elaborar haces de ideas que podrían articularse conjuntamente en un mismo proyecto o, al menos, caracterizarlo o delimitarlo temáticamente. Bastantes de las ideas de la segunda lista, la que aparece en la Segunda Carpeta, se relacionan temáticamente con una obra édita del autor: La bomba increíble, la fabulación distópica que publicó en 1950 como respuesta al espanto causado por las dos bombas atómicas con las que EE. UU. Pusieron el broche final a la Segunda Guerra Mundial. No resulta en absoluto descartable que estos listados formaran parte de la fase preparatoria de la fabulación y que constituyan el testimonio de ciertos caminos desechados en el proceso de selección y de otros que tuvieron continuidad y fueron textualizados en esa narración (el templo, la ciudadela, el museo). Estos elementos se habrían transformado en la redacción, virando hacia un planteamiento menos radical y extremo, más mimético y verosímil en la versión publicada. Estas ideas esbozan una visión de la realidad mucho más inhumana, dominada por lo tecnológico y lo racional, en plena eliminación de cualquier rastro emocional o cultural (música, literatura, en definitiva aniquilación del alma). Estas listas sugieren una confrontación más radical con ese hipotético futuro, pero resulta más que probable que el escritor prefiriera matizar esa dictadura tecnológica que denuncia la novela, haciéndola más verosímil y por lo tanto, elaborando una narración menos fantástica. Por lo tanto, este pre-texto no funciona tanto como una hipótesis de futuro sino como material, que junto con los borradores de La bomba increíble, pertenecería al proceso escritural de ese proyecto. El «Apunte de ideas» de la «Primera carpeta», en cambio, sí parece contar con entidad suficiente y proyectarse en solitario hacia una posible reelaboración y reescritura posterior. Temáticamente, no se relaciona con ninguno de los textos publicados o inéditos. Estas ideas se adentran en la investigación del choque entre la apariencia y la realidad oculta que tan grata fue al autor en su última época.

2) Proyectos narrativos de tipo germinal, brevemente desarrollados, que constituyen el primer paso del incipiente proceso redaccional. Este estadio, pese a ser bastante primitivo, esboza el planteamiento de los ejes argumentales y los rasgos básicos de los personajes, plasmado todo ello de un modo claramente redaccional. En definitiva, textualiza el andamiaje sobre el que se eleva una narración. Estos trece textos testimonian, sin duda ninguna, la fase posterior a los «apuntes de ideas». Presentan una mayor complejidad, muestran la elección y el descarte de diversos caminos y un desarrollo más avanzado. Representan una narración marcada únicamente por la lógica de la evolución argumental, un argumento en progreso, unido por lazos causales y consecutivos. 
Si bien el conflicto principal y los rasgos que caracterizan a los personajes aparecen certeramente perfilados, muchos son los «blancos» o aspectos sin especificar. Estos aspectos sin definir se refieren normalmente a los nombres de los personajes, al cuándo y al dónde se produce el conflicto y a posibles acciones secundarias o complementarias. La textualización de este tipo de datos constituirá la mejor prueba de que se trata de una información importante. Por ejemplo, en el caso de "La ruptura» el nombre de los personajes, Mildred y Mario, cobra una especial significación porque el de él es una prueba de su nacionalidad y cultura y esa información funciona como indicio del motivo por el que estallará el conflicto. En cambio, en el caso de "La impostora» los nombres se indican a través de iniciales, pero el lugar donde sucede la acción se especifica claramente, pues es fundamental para sustentar la verosimilitud del desvarío del personaje femenino que la acción se desarrolle en una clínica. Las tramas secundarias, evidentemente, no se suelen aludir, su introducción será posterior, al igual que la complejización, la humanización de los personajes o la labor de estilo. Lo habitual es que presenten ya un título, pero resulta muy significativo del relativismo con el que afrontaba el proceso el hecho de que en varios de estos proyectos encontremos más de uno (pueden ser incluso tres, como en el caso de «Los estragos de la ilusión. Los anuncios. El moralista»). Este planteamiento de diversas posibilidades demuestra que el autor se planteaba la redacción como una búsqueda entre diversas posibilidades y no como un proceso rígidamente determinado desde su inicio.

Estos textos pueden alojar en sí dos fases sucesivas. Resulta evidente que algunos de ellos son fruto de una primera redacción manual; otros, en cambio, aparecen mecanografiados, con muy pocas correcciones, lo que podría apuntar hacia otro tipo de primera redacción o incluso hacia un proceso de ampliación. Estos "proyectos narrativos», por lo tanto, testimonian dos tiempos de una misma fase inicial de la redacción. Pedro Salinas, como él mismo reconocía, tenía una letra endiablada, angulosa y extendida, fruto de un ritmo rápido y de un enérgico impulso de textualización ${ }^{12}$. Por

12. En la narración «El desayuno» no resulta difícil descubrir el guiño que el autor se hizo a sí mismo, siempre consciente de la dificultad de su caligrafía, cuando humorísticamente describe la escritura de una de las protagonistas: «los rasgos se le desmandaban, sobre la hoja, tropilla de potros indómitos, que se encabritan, que cocean, que se arrojan de las curvas de sus lomos las significaciones que les querían cargar encima. Los ojos de las letras, sin cerrarse nunca; los palos de las eles disparados hasta mitad del renglón de arriba; los rasgos transversales de las tes, espadachines, acuchillando, furiosos, a los vocablos de vecindad. Enzarzábanse las palabras unas en otras, y los renglones, al sentir la proximidad del borde del papel, se mustiaban, declinaban, lánguidamente, como ramas de sauce, perdida ya toda pretensión de horizontalidad» (2007 vol. I: págs. 905-906). El autor, por esa razón, prefería 
eso, los folios que presentan una escritura manual parecen responder a una redacción apresurada, fruto del deseo de plasmación y fijación de los aspectos principales del argumento para que no caigan en el olvido; los textos mecanoscritos, por su parte, muestran una voluntad de claridad, de fijar el texto en un proceso que, en algunos de los materiales, se ve afectado por un movimiento de expansión.

Así pues, en estos "proyectos narrativos» la escritura funciona ciertamente como «sinónimo de reescritura» (Lois: 2001, pág. 43). La combinación de operaciones que caracterizan estos proyectos muestran un "rehacer» constante en el devenir redaccional. Se trata de un proceso sinuoso y complejo, marcado por "caminos que se intentan, se cancelan, se vuelven a intentar» (Barrenechea: 1983, pág. 26) y caracterizado por un impulso hacia la expansión que determina el avance del proceso redaccional. Por eso mismo, esta primera fase de la prosa saliniana deja diversas aperturas en el texto para las fases plenamente redaccionales. En la búsqueda que escenifican estas operaciones repetidas surge la imagen del «taller del escritor».

Algunos materiales muestran la mayor complejidad de esta fase. La coincidencia en la temática de varios "proyectos narrativos» apunta hacia un proceso de reelaboración interna, que se efectúa dentro de este primer movimiento redaccional. Esta reescritura implica una expansión y una complejización que apunta a que esta primera parte del proceso podía ser más larga y sinuosa de lo que pudiera parecer. Así lo demuestra el hecho de que «Los inseparables o el desconsolado esposo» parezca una fase previa a «La muerte vencida o los progresos de la ciencia». En el desarrollo creativo que conduce de un proyecto a otro se aprecia la búsqueda de una perspectiva más múltiple, una mayor complejidad y una presencia más evidente de consideraciones morales.

La coincidencia temática de "Las dos monedas» y «Los falsificadores» también puede resultar sospechosa. Ambos proyectos giran sobre un eje temático central: un conflicto suscitado por la existencia de billetes falsos. Una revisión profunda muestra que el texto titulado «Los falsificadores» incluye en sí mismo dos fases. Este folio recoge un proceso de escritura, reflexión y reescritura marcado por la expansión, el ahondamiento de la perspectiva moral y la introducción de nuevos matices temáticos. Sin embargo, «Las dos monedas» $\mathrm{y}$ «Los falsificadores» constituyen dos esbozos

escribir a máquina para no causar problemas de lectura a los receptores de sus cartas, hasta tal punto que llegaba a insistir en ello en sus misivas. Así lo demuestra la post data de la carta que el 1 de agosto de 1932 envió a Katherine Whitmore: «Perdona esta carta tan larga y esta letra tan mala. ¿¿Sabrás leerla?» (2007 vol. III: pág. 287). 
con entidad y personalidad propia. Pese a lo equívoco que resulta que ambos giren en torno al asunto del engańo monetario, cada proyecto se caracteriza por un desarrollo narrativo individual característico que permite constatar que no constituyen dos fases de un mismo relato, sino dos textos que surgen de una misma inquietud, un hecho habitual de la obra de Pedro Salinas, como demuestra la perspectiva común que enlaza las narraciones de cada una de sus colecciones.

El tipo de lenguaje que caracteriza los «proyectos narrativos» comparte con los «apuntes de ideas» una férrea voluntad de plasmar las ideas básicas de un modo breve y escueto. Sin embargo, en este caso se trata de oraciones más extensas, aunque carentes de conectores, que se enlazan unas con otras asentándose en el devenir lógico del texto para sustentar el desarrollo de la narración. En lo que concierne a los signos ortográficos, aunque los dos puntos muestran las mismas relaciones que se señalaban en los «apuntes», coma y punto y coma son ahora de gran utilidad para ordenar y jerarquizar ideas. Se trata de oraciones algo más complejas, junto a las simples (que el autor utiliza para resaltar los aspectos más destacados) también encontramos subordinadas y coordinadas que plasman la multiplicidad de la idea o de los hechos narrados. Se recurre a la enumeración, en esa búsqueda de la claridad expositiva y del orden lógico de los argumentos; se enumeran las tramas intercaladas («La impostora»), los motivos principales («Los inseparables o el desconsolado esposo») o los temas de los diversos subapartados («El botín planificado»).

Atendiendo a la forma que presentan los textos, resulta innegable que varios fueron sometidos a nuevas lecturas y correcciones por parte del autor. El análisis de estos aspectos es de gran utilidad para comprender los métodos de trabajo del escritor y alumbran un proceso caracterizado por las dudas, las transformaciones, las sustituciones y las certezas. Las cartas se perfilan como elementos paratextuales de indudable valía, pues testimonian un proceso de escritura caracterizado por la intensidad alcanzada en breves pero fecundos períodos. Esta intensidad implica que los materiales, incluso los proyectos, se encuentran sometidos a revisiones, tanto inmediatas como de lectura pausada (aunque estas son más propias de fases redaccionales más avanzadas, como demuestran los borradores de El valor de la vida, La bomba increíble y El desnudo impecable y otras narraciones). Las correcciones a máquina se sitúan en el momento de la redacción, al eliminar lo que se considera insatisfactorio; estas variantes sincrónicas, denominadas también inmediatas o de escritura (Grésillon: 1994, pág. 70), muestran la relectura inmediata a la que el autor sometía estos materiales. La amplificación a través de la inserción de palabras, sintagmas u oraciones funciona también de modo 
paralelo a la redacción. Estas correcciones apuntan hacia una voluntad de matización o ampliación de la información o del estilo. Lo que nunca encuentra el investigador son casos de alternativa no resuelta (Grésillon: 1994, pág. 144), aquellos en los que se plantean dos variantes posibles y el autor opta por no escoger ninguna; si bien esto es habitual en los borradores que pertenecen a fases posteriores, los «proyectos narrativos» no plantean ese tipo de disyuntivas, más bien un abanico significativo de posibilidades aún por decidir. Evidentemente, estas modificaciones tienen menor entidad que las que surgen en fases posteriores, pero son un indicio significativo de un proceso creativo en movimiento, inmerso en un desarrollo que implica comenzar a asumir caminos y desechar posibilidades.

Por último, es necesario mencionar varias "notas de control», esto es, anotaciones metatextuales que permiten al investigador acercarse al «juicio del escritor sobre lo que escribe, un acto de reflexión sobre sí mismo» (BelleminNoël: 2008, pág. 72). Estas anotaciones se proyectan sobre el futuro de las siguientes fases redaccionales, con el fin de poder trazar con esta reflexión presente un camino posible, pues indudablemente cabe la posibilidad de que en ese futuro fueran descartadas. Se trata de modos de orientar vacíos de información o estructuras o de plantear estrategias que el escritor se sugiere a sí mismo para una redacción futura. En «Los falsificadores», por ejemplo, cuando se alude al caso que impresionó al joven policía en la infancia, prefiere continuar con el hilo argumental en lugar de esbozar este suceso intercalado, por lo que anota como recordatorio que debe «inventarlo»; en el caso de «El crimen» esa nota resulta aún más explícita, pues plantea una posible estrategia narrativa consistente en utilizar el diario del criminal, combinándolo con relato enunciado por el detective que lleva el caso. Estas notas orientan el desarrollo posterior sin imposiciones, postergando la decisión de asumir o descartar sus propias sugerencias.

\section{Coincidencias, inQuietudes Y MOTIVOS DE LOS «Proyectos de Cuentos»}

La inmersión en el "taller de escritura» de Pedro Salinas ofrece al investigador la posibilidad de acercarse más a la comprensión del pensamiento vital y literario del escritor, pero también al conocimiento de su vivencia del ambiente social, político y cultural en que desarrolló su labor en el exilio. Las líneas que configuran estos folios no dejan lugar a dudas: la inquietud ontológica dominante durante los años de exilio impulsa la escritura saliniana 
de modo decidido hacia el desvelamiento de la realidad oculta, aquella cuyo conocimiento resulta arduo y complicado, pero debe ser llevado a cabo pese a las peligrosas consecuencias.

Estos "proyectos narrativos» $\mathrm{y}$ «apuntes de ideas» dibujan una situación dominada por la falsedad y las apariencias, una realidad que los personajes perciben como verdadera y que no lo es en absoluto. En este sentido, existe una coincidencia muy significativa en el conflicto que casi todos desarrollan. La atención se proyecta sobre un personaje central, al que se sitúa fuera del sistema dominante, porque se trata de alguien que, una vez constatada su naturaleza falaz, no se conforma con la imagen falsa que domina la realidad y trata de superarla. Más que como una posibilidad que es posible escoger o desechar, ese proceso se traza en estos archivos como un impulso o necesidad vital de marcado carácter ético. Se trata de un proceso al que el hombre debe enfrentarse, quiera o no. El conflicto surge porque el posible protagonista siempre desafía a fuerzas, intereses o personajes que se oponen a su proceso de desvelamiento y aquellos no están dispuestos a que esa realidad irreal sea alterada, pues conviene a sus intereses.

Estos "proyectos» $y$ «apuntes» perseveran en la línea que desarrolla el resto de la narrativa del autor, en un eterno impulso por desvelar el conocimiento de lo esencial. De hecho, resulta muy significativo que esa situación, a raíz del exilio, se vuelva mucho más conflictiva en su escritura creativa, pero también en su propia existencia, como testimonian sus epistolarios. Salinas, sagaz observador de la realidad en la que vivía, concebía la literatura como una herramienta de conocimiento de la vida (como llegó a asegurarle a Katherine Whitmore «los grandes libros y la vida no son cosa distinta [...] Todo lo que lees tiene un eco no ya en tu juicio, en tu razón, sino en tu vida entera» [2007 vol. III: pág. 467]). Por esa misma razón, su propia escritura se constituye en modo de comunicación y desvelamiento de esa vida para el lector atento. Por esa razón, su propio proceso cognoscitivo emerge en cada uno de esos proyectos, testimoniando una preocupación vital que marcó sus últimos años de vida.

El conflicto puede presentar aspectos muy diversos. Se produce fundamentalmente entre la verdad difícilmente cognoscible y una apariencia irreal. No obstante, en estos procesos esa colisión adopta diversas apariencias, lo que no impide que se encuentren íntimamente relacionados por la inquietud común de la que afloran. Las tensiones que afectan a la relación del individuo con su entorno se formulan en una jerarquía cambiante, pero los elementos comunes confirman la existencia de un paradigma estable. La dualidad que conforma siempre el ser de la realidad puede proyectarse, en un nivel temático, sobre el ámbito del poder, tanto en su vertiente política como 
económica. Los conflictos a los que el individuo se debe enfrentar a causa de los abusos, excesos o engaños de los políticos, los bancos u otro tipo de elementos son múltiples. «Proyectos de cuentos» como «Los falsificadores», «Las dos monedas» o "La muerte vencida o los progresos de la ciencia» exploran los inestables límites entre verdad y mentira en conflictos en los que el gobierno y los poderes económicos siempre optan por mantener la falsa verdad para no desestabilizarse o poner en peligro su credibilidad. Ante el engaño de los poderosos, el personaje que se enfrenta a ellos siempre parece abocado al fracaso.

El cuestionamiento de la ciencia y la tecnología como falsos relatos elaborados por el poder es una constante que recorre la escritura del exilio. Estos proyectos atestiguan el lado opuesto de lo que en sus textos de los años 20 había sido una fascinación entusiasta, que dio paso a una conciencia aguda de su peligro, tras constatar el poder de manipulación y de destrucción que habían alcanzado; como le dirá con gran pesimismo a Claudio Guillén en una de sus últimas cartas:

Cada día me siento más asombrado del empeño y del esfuerzo que el hombre moderno está poniendo en destrozar lo que desde hace veintitantos siglos le daba la única razón de ser por encima de la bestia. En esa empresa la técnica le está sirviendo de un modo admirable (2007 vol. III: pág. 1481).

Algunos de los «apuntes de ideas» van más allá de la alerta para elevarse como una acusación clamorosa contra la utilización interesada e inhumana del poder científico. «El botín» y «Los inseparables o el desconsolado esposo", por su parte, indagan en su engañoso uso, mostrando cómo se crean y elaboran estrategias moralmente inaceptables para satisfacer necesidades humanas a través de engaños, como las falsas grabaciones de las mujeres muertas que hacen que sus esposos mantengan la ilusión de que siguen vivas, pese a saber con certeza que no lo están. Bajo ese conflicto siempre aparece en los "proyectos narrativos" un segundo nivel, de menor visibilidad pero de honda trascendencia, que constituye el sustrato ético sobre el que se asientan. Se trata del planteamiento de un conflicto moral, en el que el protagonista (y por ende, el lector) se debe enfrentar a la cuestión clave de si resulta éticamente aceptable la mentira en cualquiera de sus formas. Esta inquietud puede surgir del planteamiento de un engaño económico, de un subterfugio que mediante falacias calma el sufrimiento o de una ley que convierte en lícito lo que no lo es. Estos "proyectos narrativos» parecen planteados para remover la conciencia del lector, formulados como una provocación que desequilibra e impulsa el replanteamiento de cuestiones éticas y morales 
que no se pueden separar de una situación de crisis como la que afrontó el mundo occidental en los años 40 y principios de los 50 .

Otros aspectos propios de la incipiente realidad posmoderna encuentran también acomodo en estos esbozos. Textos como «La ruptura» y «La muerte vencida» hacen emerger cuestiones tan interesantes y perturbadoras como la incomunicación, la soledad y los engaños que atenúan el duelo tras la muerte de un ser amado, gracias a los cuales realidad y ficción explicitan las tenues fronteras que los separan. Por su parte, otros proyectos exploran aún más los límites de la narrativa y afrontan cuestiones que si bien habían sido formuladas de modo tímido anteriormente, se presentan aquí de un modo más extremo. "La impostora», «El crimen» o «La apuesta» exploran, como no lo habían hecho los textos narrativos salinianos anteriormente, los borrosos límites entre cordura y locura y ponen de manifiesto su naturaleza equívoca y la facilidad con la que se pueden traspasar, incluso en las situaciones más absurdas y por parte de candidatos impensables a priori. Estos límites se destruyen a través de la creación de una tensión que va más allá del desvarío para sumirse en la esquizofrenia. Lo característico es que esa tensión no se resuelva, que estos esbozos carezcan de resolución explícita o que el planteamiento finalice abruptamente. Este motivo se encuentra estrechamente vinculado con la investigación de la dualidad racional/ irracional o racional/sobrenatural que tan buenos resultados le dio al autor en sus obras éditas, La bomba increible y El desnudo impecable y otras narraciones (1950 y 1951), y se inscribe en el cuestionamiento de los excesos racionalistas y cientifistas que tanto preocuparon a Pedro Salinas en su exilio.

En definitiva, todos estos hilos conducen hacia el conflicto entre la verdad esencial, siempre múltiple y compleja, y la falsa apariencia de sencillez y lógica. "La partida de ajedrez», por ejemplo, apunta certeramente hacia una de las inquietudes centrales de la prosa del autor: la existencia de una dimensión sobrenatural que se oculta bajo la realidad de un mundo racionalmente ordenado. Aunque no sea nombrado explícitamente, la presencia del «seguro azar» saliniano contribuye a poner de manifiesto esa falsa apariencia, pues estos sucesos son los que ponen de manifiesto la diversidad de niveles de la realidad. En boca de Aurelia, uno de los personaje de «El autor novel», se halla una de las definiciones más certeras del «seguro azar»: se trata de "sucesos que no sirven como los otros, para este o aquel fin, que se te aparecen sin pensarlos y te descubren vistas de un mundo donde las cosas no pasan como aquí, que no se rige igual» (2007 vol. I: pág. 990). Su irrupción en la monótona existencia constituye un primer paso para que los personajes pongan en marcha el proceso cognoscitivo que los llevará al desvelamiento de la realidad; indudablemente, los proyectos 
continúan esta investigación cambiando la perspectiva y ahondando en la realidad.

Estos «apuntes» y "proyectos», como ya se ha señalado, presentan una continuidad sostenida con los rasgos que determinan la escritura exílica saliniana. Por eso, tanto la relación amorosa como las relaciones intertextuales que abordan no pueden ser consideradas aisladamente, sino en relación con el resto de su obra. Esbozos como «La partida de ajedrez» desarrollan esa temática en relación con lo sobrenatural, pero el resto parece apuntar hacia la voluntad del escritor espańol de ir más allá, explorando nuevas posibilidades narrativas. "La muerte vencida o los progresos de la ciencia» y "Los inseparables o el desconsolado esposo» tratan el tema de la muerte de uno de los componentes de la pareja para poner de manifiesto que, después de su desaparición, el que queda no puede consolarse falsamente tratando de creer que su cónyuge no ha muerto. Los principios éticos se sitúan siempre en estos esbozos últimos por encima de la investigación de las relaciones amorosas.

En el caso del aspecto intertextual, «apuntes» y «proyectos» constituyen una muestra de la voluntad de Salinas de seguir dialogando con los grandes relatos de la tradición cultural, ya sea en su vertiente mítica o literaria. Los «apuntes» de la segunda carpeta, por ejemplo, son muy representativos al respecto. Tras la oración "La historia de los errores de la humanidad», el escritor anotó tres grandes obras literarias: La Ilíada, El Quijote y Romeo y Julieta. Resulta lógico suponer que en el contexto en el que esta anotación aparece, dentro de una lista de ideas en la que se plantea la sustitución de elementos naturales por otros artificiales, habría pensado en utilizar estos textos clásicos como irónicos «ejemplos» de la dañina locura del hombre, causada tanto por la literatura como por el amor. No obstante, el texto fundamental con el que el escritor establece su diálogo exílico, acometiendo su revisión y dotándolo de nuevos sentidos, es la Biblia. Y, a la vista de "Los estragos de la ilusión. Los anuncios. El moralista» resulta evidente la voluntad de continuar esa reflexión sobre la pervivencia de los relatos bíblicos. En el contexto del relato sobre un hombre que atrae a las masas con equívocas ofertas que resultan ser inexistentes, este "proyecto" tan crítico con los excesos consumistas se cierra con una imagen de gran impacto: desde un avión se lanza una imagen de Jesús en la que aparece arrojando a los mercaderes del templo. A través de estas alusiones y recreaciones, el autor establece con otros saberes un diálogo en el que no sólo se autolegitima reformulando esos motivos, sino que les da continuidad al mismo tiempo que los matiza y revitaliza, mostrando que en el siglo XX están tan dotados de sentido como en los albores del cristianismo. En definitiva, este diálogo 
reafirma que muchas de esas enseñanzas son aún necesarias para el hombre de hoy, pues las mismas cuestiones jalonan su existencia, una y otra vez, muestra de un tiempo cíclico que caracteriza la historia de la humanidad.

\section{Aportaciones de los esbozos Del «TAller De EsCritura»: CONOCIMIENTO DE LA ARQUEOLOGÍA CREATIVA}

Un «dossier genético» debe dar cuenta no solo dela localización y clasificación de los archivos, sino también abordar la descripción e interpretación de los materiales. La investigación sobre algunos de los aspectos más desconocidos del archivo saliniano permite desvelar como en ningún otro caso las huellas de los primeros pasos del proceso escritural. Por eso, esta inmersión en los "proyectos narrativos» y "apuntes de ideas» ha tratado de tender un puente hacia el conocimiento de los materiales de trabajo del escritor y hacer emerger el conjunto de procesos que los caracterizan, pues solo de ese modo se podrá producir el desvelamiento de «los mecanismo de la escritura y así lograr un conocimiento fundamentado de los actos materiales e intelectuales de la creatividad verbal» (Lois: 2001, pág. 8).

El estudio de los archivos de los escritores, cuando existe, se plantea para el investigador actual como un paso imprescindible para constatar la existencia de materiales que albergan en sí la oportunidad de un texto posible y que han permanecido fuera del ámbito público. No sólo porque, como en el caso de estos "Proyectos de cuentos», pueden atesorar proyectos desconocidos o inéditos, sino porque al prescindir de su conocimiento se está renunciando al conocimiento global de todos los aspectos, tanto propiamente textuales como complementarios, que caracterizan la obra de ese autor. Diversos movimientos de creación surcan los archivos de un escritor, como resulta evidente en el caso de Pedro Salinas, y aún lo será más si se continúa la investigación; proyectos, líneas temáticas y estrategias escriturales desechados aportan una información tan importante como aquella que se textualiza en la obra publicada.

Los «Proyectos de cuentos» que durante años se han mantenido en el aislamiento del archivo bostoniano constituyen el indicio más rotundo de que la narrativa ocupaba un lugar destacado en el marco del impulso escritural en el ocaso de la vida del autor español. Revelan que ese género, diverso y tan problemático como se dibuja en este «taller de escritura», se proyectaba hacia el futuro con una voluntad de continuidad que hasta ahora no había sido descubierta. Por su propia naturaleza prerredaccional o redaccional primigenia constituyen un testimonio fundamental de las primeras fases de escritura, abriendo el camino hacia un mayor grado de desvelamiento de la 
naturaleza y los procesos que caracterizaban su proceso creativo. La escritura de Pedro Salinas, a la luz de estos materiales, podría situarse entre lo que Grésillon denomina "l'écriture à programme et l'écriture à processus», esto es, a medio camino entre la textualización que sigue un programa preestablecido y los impulsos o ideas que aparecen espontáneamente, sin programación previa (1994: pág. 102). Se trata de una escritura delineada en sus rasgos básicos, pero que asume plenamente la posibilidad de ir completándose en su propio proceso; es más, deja las puertas abiertas a la integración posterior de diversos elementos que van desde personajes secundarios a tramas complementarias, los modos del discurso o las estrategias narrativas.

Resulta innegable que estos esbozos desvelan de un modo sutil los discursos sociales dentro de cuyo seno surgen, confirmando que la escritura "recoge en su interior tensiones del proceso social en que está inmersa» (Lois: 2001, pág. 43). Y sin embargo, eso no excluye que en estos "proyectos»y «apuntes», pertenecientes a un ámbito privado, se pueda rastrear el vaivén psicológico y emocional que constituye la huella de la mano que escribe, los indicios de los impulsos, las obsesiones, los deseos y los rechazos que caracterizan su movimiento creativo. La lucha por el desvelamiento de la realidad externa e interna, el eje fundamental sobre el que circula el impulso cognoscitivo que es la raíz de la escritura saliniana, funciona como lugar de encuentro entre los vaivenes históricos y psicológicos que convergen en estos folios, en los que encuentra una formulación multisemiótica que busca agotar todos los caminos en un proceso incansable.

Así pues, este material no debe ser apreciado únicamente como complementario, un elemento ideal para abordar nuevas perspectivas para el conocimiento de los géneros mayores del autor, sino como un modo de reorientar la comprensión de la obra creativa de Pedro Salinas en todos sus niveles, espacios y significados, en una búsqueda de discursos, procesos y sentidos que atraviesan las fronteras temporales y de género. No es posible obviar que estos «Proyectos de cuentos» constituyen una oportunidad magnífica de conocer los modos en que se desarrollaba la escritura saliniana (su nacimiento, sus metamorfosis, sus descartes y aciertos) de un modo más nítido que acudiendo a las versiones publicadas, adentrándonos en la intimidad del «taller del escritor» para conocer no sólo sus entresijos sino también sus procesos escriturales, su cronología vital y su proyección creativa. Estos «proyectos» y «apuntes» alumbran una parte valiosa de la historia literaria, la que compone dentro de la obra de un escritor «una historia secreta, casi siempre ausente de las biografías literarias, y que constituye, sin embargo, lo esencial de lo que nos gustaría saber sobre el autor» (Biasi: 2008, pág. 115). 
BULLETIN HISPANIQUE

\section{BiBLIOGRAFÍA}

Barrenechea, Ana María y Cortázar, Julio, Cuaderno de bitácora de "Rayuela», Buenos Aires, Sudamericana, 1983.

Bellemin-Noël, Jean, «Reproducir el manuscrito, presentar los borradores, establecer un ante-texto", en Genética textual, comp. de Emilio Pastor Platero, Madrid, Arco Libros, 2008, págs. 53- 78

Biasi, Pierre-Marc de, «¿Qué es un borrador? El caso Flaubert: ensayo de tipología funcional de los documentos de génesis», en Genética textual, comp. de Emilio Pastor Platero, Madrid, Arco Libros, 2008, págs. 113-151.

Colla, Fernando (coord.), Archivos. Cómo editar la literatura latinoamerican del siglo XX, Poitiers, CRLA-Archivos, 2005.

Fernández de Andrada, Andrés, Epistola moral a Fabio y otros escritos, ed. de Dámaso Alonso y estudio de Juan F. Alcina y Francisco Rico, Barcelona, Crítica, 1993.

Grésillon, Almuth, Eléments de critique génétique. Lire les manuscrites modernes, Paris, Presses Universitaires de France, 1994.

Hay, Louis, "Del texto a la escritura», en Genética textual, comp. de Emilio Pastor Platero, Madrid, Arco Libros, 2008, págs. 35-52.

Lois, Élida, Génesis de escritura y estudios culturales. Introducción a la crítica genética, Buenos Aires, EDICIAL, 2001.

- «Bases teóricas», Archivos. Cómo editar la literatura latinoamericana del siglo XX, coord. por Fernando Colla, Poitiers, CRLA-Archivos, 2005, págs. 45-124.

Lluch Prats, Javier, «Un diálogo pendiente entre dos orillas. Aspectos de la crítica genética en ámbito hispánico», Recto/Verso, 2, diciembre 2007, http://www. revuerectoverso.com/spip.php?article75, 3 de diciembre, 12:20.

Manrique, Jorge, Poesía, ed. de Vicente Beltrán y estudio de Pierre le Gentil, Barcelona, Crítica, 1993.

Pastor Platero, Emilio, «La crítica genética: avatares y posibilidades de una disciplina», en Genética textual, comp. de Emilio Pastor Platero, Madrid, Arco Libros, 2008, págs. 9-32.

Quevedo, Francisco de, Obra poética, ed. de José Manuel Blecua, vol. I, Madrid, Castalia, 1969.

Salinas, Pedro, «Proyectos de cuentos», bMS Span 100 (1020)( 2 carpetas).

- «Últimos escritos», bMS Span 100 (1081) (3 carpetas).

- «Un conocido por conocer», 3, 1921 [reproducción en facsímil, Madrid, El Museo Universal, 1987, págs. 57-58].

- «Delirios del chopo y el ciprés», Revista de Occidente, IV, 1924, págs. 145151.

- «Volverla a ver», Sí. Boletín Bello Español del Andaluz Universal, I, 1925, págs. 1-8.

- «Entrada en Sevilla», Revista de Occidente, IX, 1925, págs. 145-152. 
- «Aurora de verdad», Revista de Occidente, XIII, 1926, págs. 1-7.

- Vispera del gozo, Madrid, Revista de Occidente, 1926.

- La bomba increíble, Buenos Aires, Sudamericana, 1950.

- El desnudo impecable y otras narraciones, México, Tezontle, 1951.

- El valor de la vida, ed. y estudio de José Paulino Ayuso, Sevilla, Renacimiento, 2009.

- Dos prosas inéditas (entre la ironía y la sátira), Madrid, Devenir, 2010 [en prensa].

- Obras completas, vol. I, II y III, ed. de Enric Bou, Andrés Soria Olmedo (ensayo, vol. II, y epistolario, vol. III) y Montserrat Escartín (poesía, vol. I), Madrid, Cátedra, 2007.

Vara Ferrero, Natalia, La narrativa de Pedro Salinas, Leioa, Universidad del País Vasco, 2010. 
